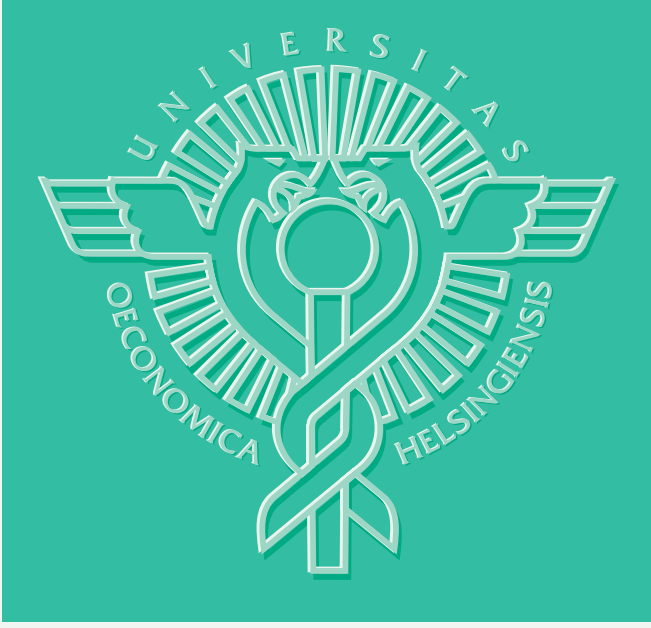

Antti Pirjetä - Vesa Puttonen

\title{
STYLE MIGRATION IN THE EUROPEAN MARKETS
}




\section{Antti Pirjetä - Vesa Puttonen}

\section{STYLE MIGRATION IN THE EUROPEAN MARKETS}

A Financial Markets and Services Research Paper

For more finance related research at HSE, see www.hse.fi/fms/

May

2007 
HELSINGIN KAUPPAKORKEAKOULU

HELSINKI SCHOOL OF ECONOMICS

PL 1210

FI-00101 HELSINKI

FINLAND

(C) Antti Pirjetä, Vesa Puttonen and Helsinki School of Economics

ISSN 1235-5674

(Electronic working paper) ISBN 978-952-488-145-6

Helsinki School of Economics -

HSE Print 2007 


\title{
Style migration in the European markets*
}

\author{
Antti Pirjetä and Vesa Puttonen \\ Helsinki School of Economics \\ P.O. Box 1210, FIN-00101 Helsinki \\ E-mail: antti.pirjeta@hse.fi, vesa.puttonen@hse.fi
}

May 23, 2007

\begin{abstract}
We use data on 531 largest European stocks to measure the performance of simple value and growth styles against the index. Portfolio theory is applied to find the maximum Sharpe ratio and to compare the efficiency of value and growth styles. Multivariate test of alphas shows that the benchmark index is inefficient, and a value strategy based on $\mathrm{P} / \mathrm{BV}$ is less inefficient. Our data suggests value stocks are avoided, because their earnings are less stable and return on invested capital is lower compared to growth stocks. Finally, stocks that migrate from value to growth provide superior raw and risk-adjusted returns.
\end{abstract}

\section{Introduction}

It remains a puzzle in empirical asset pricing that the relative valuation of equities is strongly correlated with current returns in the cross-section (see e.g. Fama and French [6],[7]), however the power of relative valuation measures to predict future returns is quite limited. Lewellen [14] finds that book-to-market ratio, dividend yield or earnings yield alone explain about $1 \%$ of variance of returns, although all three are statistically significant. This is likely due to empirical characteristics; stock returns exhibit high variance, but relative valuation is persistent. For example, book-to-market, earnings yield and dividend yield have autocorrelations close to one in the Lewellen [14] study. We add to this literature by showing that despite the persistence, some stocks experience major changes in valuation over the short term, and these changes are predictable to an extent. Because changes in valuation imply that a value stock becomes a

\footnotetext{
*We are grateful to Markku Kaustia and Tuomo Vuolteenaho for useful comments.
} 
growth stock or vice versa, in other words it migrates from one style to another, we speak of style migration.

We also look at returns on value and growth styles and associate the difference in alphas to differences in certain accounting variables. These are return on invested capital (ROIC), earnings yield (EY) and operating margin. Note that ROIC is based on book value of debt and equity, but EY is based on market value of equity. We repeat the value-growth classification at the end of period to discover style migration. Because it follows from changes in relative valuation (measured here by $\mathrm{P} / \mathrm{BV}$ ), we use a logit model to associate the dynamics of valuation with two accounting variables, being return on invested capital and earnings yield. The model is similar in spirit to Wang [19], who applies the logit model to predict value and size return spreads using the Fama-French factors as covariates.

Instead of predicting stock returns or scaled prices, we estimate the odds that a given stock's price-to-book ratio is over the market median at horizon. Because the response is a dichotomous variable that uses the median $\mathrm{P} / \mathrm{BV}$ as cutoff point, this approach does not make strict assumptions or require stationarity of stock price distribution. In our data the nonstationarity is seen as increasing $\mathrm{P} / \mathrm{BV}$ medians of value stocks and decreasing $\mathrm{P} / \mathrm{BV}$ medians of growth stocks. The style migration model adjusts for market-wide temporal changes in valuation.

Given that the benchmark index is found to be inefficient, we ask how much one can improve performance with simple strategies, based on ex ante determined portfolio weights? Theoretical results of Roll [17] and MacKinlay [16] show that combining an inefficient index with an orthogonal portfolio yields an improvement in the risk-return tradeoff.

In practice, we operate in a simple CAPM framework, given that index return explains at least $90 \%$ of variance in returns, even though there is some dispersion in alphas. Our estimates of excess returns and maximum Sharpe ratio use MSCI Europe as benchmark index. One of the key results is that a simple value strategy catches some of the improvement in risk-return tradeoff that is theoretically obtained by investing in the optimal orthogonal portfolio. Moreover, there is style migration among stocks. End-of-period growth stocks are characterized by high return on the book value of invested capital, but low return on the market value of equity (measured by earnings yield). 


\section{The asset pricing framework}

\subsection{Risk-based vs. nonrisk-based models}

If the CAPM leaves an unexplained component in the cross-section of returns, should it be attached to missing risk factors or irrationally behaving investors? Risk-based models suggest the former answer. They include various multifactor models, where increased return comes at the cost of increased risk; hence investors are assumed rational and increases in expected returns are followed by increases in risk. The alphas may also be due to measurement error in market returns due to the fact that the benchmark is an imperfect proxy for the market.

The benchmark of risk-based models is the three-factor model of Fama and French [7]. The intuition is that in addition to market risk, investors require risk premium for holding high-BE/ME stocks (HML factor) and small stocks (SMB factor). Fama and French interpret the HML factor as distress premium. While the Fama-French model fits reasonably well in historical US returns, it leaves some questions open. First, the HML and SMB risk factors cannot be derived using portfolio theory and second, empirical evidence indicates the risk factors are correlated to some extent. The critics remind that on ex post basis it is always possible to identify a model that explains the cross section of returns (see Lo and MacKinlay [15, p. 191]). Indeed, Fama and French [7, pp. 68-69] themselves admit there are other ways to construct factor portfolios that add explanatory power to the CAPM.

Nonrisk-based models associate the alphas with market frictions or investor irrationality, and they may imply arbitrage opportunities. However, the riskreturn tradeoff is limited even in the non-risk based context. This follows from the decomposition of the maximum squared Sharpe ratio proved by Ferson [8, p. 781]. He shows that the maximum squared Sharpe ratio, estimated in section 3.2 , is the sum of squared ratios of the index and an orthogonal portfolio.

Behavioral finance provides a class of nonrisk-based models. For instance, Lakonishok, Shleifer and Vishny [13] suggest that value returns are due to investors erroneously extrapolating the past performance of value and growth stocks. Our data agrees with the extrapolation model to the extent that investors are unable to foresee that value stocks improve their operating margins, as illustrated in Figure 5. In this context limited arbitrage cannot be ruled out. For example, investors may be unable to profit from relative mispricing of securities, if short-selling is limited or not allowed. Behavioral finance models 
and the limits of arbitrage are summarized by Barberis and Thaler [1].

Asset pricing models can also be viewed in the consumption-based framework, where factor risk premiums are determined by their covariance with aggregate consumption. Ferson [8] makes the connection of multifactor (or multibeta) and consumption-based models very explicit. He shows that large risk premiums are associated with factors that affect asset prices negatively when consumption is valuable (marginal utility is high). Consumption-based models also offer some theoretical advice on how many factors are needed for asset pricing. We refer to the Consumption CAPM of Breeden [2] and a spanning theorem therein that says all risk-averse investors are able to construct optimal portfolios using $S+2$ assets. Those include the riskless asset, market portfolio and $S$ portfolios most correlated with the state variables.

\subsection{Consumption CAPM}

We refer to the Consumption CAPM of Breeden [2], because it shows how the optimal risk-return tradeoff depends on correlation of asset returns with a fundamental risk factor, the consumption risk (see eqs. 1-2). Under the CCAPM the representatitive investor maximizes utility (concave in consumption) in a market, where asset price dynamics are governed by a set of state variables. Optimal investment decisions are driven by first-order conditions saying that (i) the marginal utility of consuming one euro equals the marginal utility of saving one euro and (ii) the optimal allocation depends on market prices of risk and hedging demand, i.e. dynamics of the investment opportunity set. In short-term analysis hedging demand can be ignored, and optimal portfolio weights depend only on market prices of risk and, of course, the covariance matrix of returns. We use the terms 'market price of risk' and 'Sharpe ratio' synonymously.

As pointed out by Campbell and Viceira [3], ignoring the changes in investment opportunity set leads to 'myopic' portfolio choice when applied in long-run planning. However, they add that in the special case of CRRA utility and i.i.d returns short-term and long-term investors choose identical portfolios. In our model the investment horizon is short, up to five years, and therefore we allow myopic portfolio choice.

A key property of the CCAPM is that in equilibrium the return on any risky asset depends only on aggregate relative risk tolerance ${ }^{1}$ and the asset's

\footnotetext{
${ }^{1}$ Relative risk tolerance is the reciprocal of relative risk aversion. The aggregate risk tolerance can be calculated as the sum of individual risk tolerances.
} 
covariance with aggregate consumption. It follows that the Sharpe ratios of portfolios are proportional to their correlations with consumption. Moreover, this result does not require market completeness, i.e. that perfect hedges against consumption risks were available. In equations (1-2) $\mu_{\text {opt }}$ and $\mu_{i}$ are the returns on the optimal portfolio and some arbitrary portfolio $i, T^{M}$ is the aggregate risk tolerance, and covariances with consumption are denoted $\sigma_{o p t, c}$ and $\sigma_{i, c}$.

$$
\begin{aligned}
\mu_{o p t}-r & =\left(T^{M} / C\right)^{-1} \sigma_{o p t, c} \\
\mu_{i}-r & =\left(T^{M} / C\right)^{-1} \sigma_{i, c}
\end{aligned}
$$

Equations (1-2) show that excess returns are proportional to covariance with consumption. The next step is to rewrite them using correlations instead of covariances. Since portfolio $i$ has smaller correlation (in absolute terms) than the optimal portfolio, it must have a smaller squared Sharpe ratio $s_{i}^{2}$ than the optimal portfolio's $s_{o p t}^{2}$, as shown by eq. (3).

$$
\left(\frac{s_{i}}{s_{\text {opt }}}\right)^{2}=\left(\frac{\left(\mu_{i}-r\right) / \sigma_{i}}{\left(\mu^{*}-r\right) / \sigma_{o p t}}\right)^{2}=\left(\frac{\rho_{i, c}}{\rho_{\text {opt }, c}}\right)^{2}<1
$$

Obviously, the previous result holds also for simple Sharpe ratios, if excess returns are assumed positive. We say that a portfolio is efficient when it lies on the minimum variance frontier, i.e. it yields the optimal risk-return tradeoff measured by Sharpe ratio. For later use we also need the definition of an orthogonal portfolio. Two portfolios represented by weights ( $N$-vectors) $x_{1}$ and $x_{2}$ are orthogonal if $x_{1}^{\prime} V x_{2}=0$, where $V$ is the $N \times N$ covariance matrix of returns.

In practice we work with a simple CAPM framework, where we examine the returns of $N$ portfolios. This is justified by excellent empirical fit in our data. Expected excess return for market index is $z_{p}$. It is assumed normal with mean excess return $\mu_{p} \equiv\left(\mu_{m}-r\right)$ and variance of excess returns $\sigma_{p}^{2}$. The $N$-vector $B$ represents portfolio betas. With this notation the $N$-vector of excess returns $z_{t}$ is given by equation (4), where time index $t$ runs from 1 to $T$. Further, we assume that the error terms of $N$ regressions follow multivariate normal distribution 
(denoted $M V N$ ) with zero mean and $N \times N$ covariance matrix $\Sigma$.

$$
\begin{gathered}
z_{t}=\alpha_{t}+B z_{p, t}+\epsilon_{t} \\
z_{p} \sim N\left(\left(\mu_{m}-r\right), \sigma_{p}^{2}\right) \\
\epsilon_{t} \sim \operatorname{MVN}(0, \Sigma)
\end{gathered}
$$

Equations (4) are estimated using ordinary least squares. We assume that the CAPM fit produces non-zero alphas, implying that the becnmark index is inefficient. The hypothesis that $\alpha$ is not a zero vector is tested using the Fstatistic of MacKinlay [16]. As shown by Roll [17], with an inefficient index one can construct an efficient portfolio as a linear combination of the index and the optimal orthogonal portfolio, in short OOP. It is located on the intersection of the (a priori unknown) efficient frontier and the orthogonal frontier. Roll [17] proves that the efficient portfolio is a combination of the index portfolio and the optimal orthogonal portfolio $h$. We will leave out the calculation of OOP weights, it is covered in the appendix of Roll [17]. It would be inconsistent to compare ex post constructed orthogonal (or other efficient) portfolios to ex ante constructed value and growth strategies. Excess returns to the OOP are normal with mean $\mu_{h}$ and variance $\sigma_{h}^{2}$. Because the OOP and the factor portfolios are orthogonal, one can formulate a well-defined asset pricing model (5) using the OOP. In equation (5) $\beta_{h, t}$ is the vector of asset sensitivities to the OOP and $u_{t}$ is the error term.

$$
\begin{gathered}
z_{t}=\beta_{h} z_{h, t}+B z_{p, t}+u_{t} \\
u_{t} \sim M V N(0, \Phi) \\
\operatorname{cov}\left(z_{p, t}, u_{t}\right)=\operatorname{cov}\left(z_{h, t}, u_{t}\right)=0
\end{gathered}
$$

Now take expectations of equations (4) and (5) to get $\alpha_{t}=\beta_{h} \mu_{h}$. Knowing this, we get a formula for the covariance matrix of the efficient portfolio. Excess return on the OOP is denoted $\bar{\mu}_{h}$.

$$
\Sigma=\beta_{h}^{\prime} \beta_{h} \sigma_{h}^{2}+\Phi=\alpha \alpha^{\prime}\left(\sigma_{h}^{2} / \bar{\mu}_{h}^{2}\right)+\Phi
$$

Equation (6) states that any improvement in return from using the OOP is followed by an increase in risk, which is of course a key property of risk-based models. Note that the increase in variance is inversely proportional to the squared Sharpe ratio of the OOP. This idea can be taken further by recognizing 
that the squared Sharpe ratio of the efficient portfolio $q$, given by eq. (7), is simply the sum of individual ratios.

$$
s_{q}^{2}=s_{h}^{2}+s_{p}^{2}
$$

This property is also derived by Ferson [8], who calls it the 'Law of conservation of squared Sharpe ratios'. MacKinlay [16] has shown that it is possible to get an upper bound for $s_{h}^{2}$ by using the test statistic for the significance of alphas. The upper bound for the squared Sharpe ratio gives the maximum improvement in risk-return trade-off brought by active management of equity fund compared to an index fund. Clearly, with ex ante strategies it is very difficult if not impossible to reach the upper bound. However, our empirical results suggest that value strategies can capture some of the potential improvement.

\subsection{Statistics for excess returns, Sharpe ratio and relative efficiency}

We use the method of Gibbons, Ross and Shanken [9] to test the significance of alphas in (4). They derive an $F$-statistic for the multivariate case and provide an insightful geometric interpretation for the statistic and squared Sharpe ratio of the optimal portfolio. We use the MacKinlay [16] version of the GRS test statistic. The null hypothesis is that the asset pricing model does not leave any systematic unexplained component in returns, implying $\alpha=0$. This can be tested using the statistic $\theta_{1}$ that follows the $F$-distribution with noncentrality parameter $\lambda$ defined in (10). Under the null hypothesis the distribution of $\theta_{1}$ is central $F$, i.e. $\lambda=0$. Equations (8-10) formulate the MacKinlay test statistic ${ }^{2}$.

$$
\begin{aligned}
\theta_{1} & =\left[\frac{T-N-1}{N}\right] \frac{\widehat{\alpha}^{\prime} \widehat{\Sigma}^{-1} \widehat{\alpha}}{1+\mu_{p}^{2} / \sigma_{p}^{2}} \\
\theta_{1} & \sim F_{N, T-N-1}(\lambda) \\
\lambda & =T\left[\frac{\widehat{\alpha}^{\prime} \widehat{\Sigma}^{-1} \widehat{\alpha}}{1+\mu_{p}^{2} / \sigma_{p}^{2}}\right]
\end{aligned}
$$

What makes the MacKinlay test statistic very useful is that the noncentrality parameter (10) yields directly an upper bound for the squared Sharpe ratio of

\footnotetext{
${ }^{2}$ The difference of MacKinlay and GRS $F$-statistics is that the latter statistic is calculated as $\frac{T}{T-2} \theta_{1}$. See page 1124 of Gibbons, Ross and Shanken [9]. We have $T=60$ so the difference is fairly small and does not affect empirical findings.
} 
the optimal orthogonal portfolio, as pointed out by MacKinlay [16]. To see why, note that inside the brackets in (10) the numerator equals the estimated squared Sharpe ratio of the OOP. Clearly the sample figure $\left(s_{h}^{2}\right)$ cannot be higher than the population figure $\left(s_{h}^{* 2}\right)$, because the sample figure represents local optimum and the population figure represents the global optimum. Hence we have $s_{h}^{2} \leq s_{h}^{* 2}$. Further, we know that the efficient portfolio $q$ must have higher squared Sharpe ratio than the OOP by equation (7) that implies $s_{h}^{2} \leq s_{h}^{* 2} \leq s_{q}^{2}$. Finally, check that the denominator of equation (10) cannot be less than one. Summing up this information yields the MacKinlay upper bound (11) for the noncentrality parameter $\lambda$.

$$
\lambda<T s_{h}^{2} \leq T s_{q}^{2} .
$$

This result has a clear economic interpretation. Knowing $\lambda$ from empirical data, one can calculate the implied Sharpe ratio of the efficient portfolio $q$ and then infer, whether the outcome is reasonable. If it is not, the conclusion is that there is no risk-based explanation for CAPM residuals. Note from equation (10) that the noncentrality parameter and expected value of $\theta_{1}$ increase as the riskiness of alphas decreases. The expected value of $\theta_{1}$ is given by equation (A1).

Lemma 1 presents an estimator for $s_{h}^{2}$ based on the statistic $\theta_{1}$. It follows from the distribution of $\theta_{1}$ under the alternative. This estimator represents an empirical upper bound for the improvement in risk-reward ratio brought by active portfolio management when the benchmark index is inefficient. Although Lemma 1 applies to the CAPM framework, it can be generalized to the situation with many risk factors. A similar estimator has been applied in MacKinlay [16], however without formal proof.

Lemma 1 Assume that the alternative hypothesis $(\alpha \neq 0)$ is true, hence the test statistic for excess returns $\left(\theta_{1}\right)$ follows the noncentral $F$ distribution (9). This yields the unbiased estimator (12) for the squared Sharpe ratio $\left(s_{h}^{2}\right)$ of the optimum orthogonal portfolio:

$$
\widehat{s}_{h}^{2}=\left[\widehat{\theta}_{1}-\frac{(T-N-1)}{(T-N-3)}\right]\left[\frac{N(T-N-3)}{T(T-N-1)}\right]\left[1+\mu_{p}^{2} / \sigma_{p}^{2}\right] .
$$

Equation (13) gives the conditional variance of this estimator

$$
\operatorname{var}\left(\widehat{s_{h}^{2}} \mid \widehat{\kappa}\right)=\frac{2 \widehat{\kappa}^{2}}{T^{2}}\left[\frac{\left(T \widehat{\kappa}^{-1} \widehat{s}_{h}^{2}+N\right)^{2}+\left(2 T \widehat{\kappa}^{-1} \widehat{s_{h}^{2}}+N\right)(T-N-3)}{T-N-5}\right]
$$


where $\kappa=\left(1+\mu_{p}^{2} / \sigma_{p}^{2}\right)$. Note that this assumes $\kappa$ is fixed. Given that the true squared Sharpe ratio $s_{h}^{2}$ is unknown, we use in practice the standard deviation estimator $\widehat{\sigma}\left(\widehat{s_{h}^{2}} \mid \widehat{\kappa}\right)$ to calculate confidence bounds for $\widehat{s_{h}^{2}}$.

Proof. Given in the Appendix.

Finally, we measure the relative efficiency of the benchmark index using the measure introduced by Kandel and Stambaugh [12]. It takes values from -1 to 1, and value of 1 implies that the index portfolio is ex post mean-variance efficient. The measure is calculated by running on a generalized least squares (GLS) regression in each cross-section, that is estimating $R_{i}=\gamma_{0 i}+\gamma_{1 i} E\left(R_{i}\right)$, where $E\left(R_{i}\right)$ is the CAPM expected return. Equation (14) gives the GLS estimator $\gamma_{G L S}=\left(\gamma_{0}, \gamma_{1}\right)^{\prime}$ using the following notation; $X=[\iota \quad \beta]$ where $\iota$ and $\beta$ are vectors of ones and the betas, $V$ is the covariance matrix of style returns and $E$ is the vector of expected returns.

$$
\gamma_{G L S}=\left(X^{\prime} V^{-1} X\right)^{-1} X^{\prime} V^{-1} E
$$

The Kandel-Stambaugh measure is denoted $\psi_{p}$ and it is calculated as R-squared from the regression (14); $\psi_{p}^{2}=R_{G L S}^{2}$. Table 3 reports the average $\psi_{p}$ and some descriptives from 60 cross-sectional regressions.

\section{Data description and results}

\subsection{Average returns and Sharpe ratios}

We consider an investor whose investment opportunity set consists of 600 largest listed European companies, similar to MSCI Europe or DJ Stoxx indices. Our dataset consists of returns and accounting variables (EPS, P/BV, ROIC, and operating margin) on these firms, downloaded from the databases of Thomson Datastream and Worldscope. Stock returns are measured by log change in return index (RI variable) values from Datastream and therefore include dividends. The accounting data is from Worldscope; $\mathrm{P} / \mathrm{BV}$, operating profit margin, ROIC and earnings yield correspond to fields 09304, 08316, 08376 and 09204. Risk-free return is calculated using monthly quotes of 6-month Euribor.

Four buy-and-hold style portfolios are formed at the end of December 2001 and held until the end of December 2006. This gives 60 monthly returns for the period 1/2002-12/2006, to be coupled with annual accounting data for the years 
2001-2005. The benchmark index is value-weighted MSCI Europe total return that includes dividends. Because the accounting data is missing for some firms, and some mergers and delistings take place, our sample space is close to, but does not equal the benchmark index. In order to qualify for the style portfolios, a stock must have the accounting data available and its $\mathrm{P} / \mathrm{BV}$ must be positive at the start ${ }^{3}$. The sample space includes 531 stocks at the start and 519 stocks at the end. If a stock is delisted, its terminal value is the delisting value. If two firms merge, their combined weight will be the sum of pre-merger weights. One advantage of buy-and-hold portfolios is their tractability. For example, when the $\mathrm{P} / \mathrm{BV}$ sorts are repeated at the end of period, we know exactly what firms have moved from value to growth.

The style portfolios are based on price-to-book value $(\mathrm{P} / \mathrm{BV})$ sorts. Portfolio weights are proportional to market values in all four styles. Median value invests in companies with lower than median $\mathrm{P} / \mathrm{BV}$ and the median growth style invests in companies above the median $\mathrm{P} / \mathrm{BV}$. 30-70 value invests in companies in the bottom 30\%, whereas the 30-70 growth invests in stocks in the top 30\%. While the median may be a practical breakpoint, the 30-70 division is also of interest, because it is used by Fama and French [7] to calculate the value (HML factor) premium. Because the portfolios are not rebalanced, there is no survivor bias in returns. Figure 1 plots the total return indices for our strategies, compared to the benchmark index.

Mean returns and monthly Sharpe ratios for the styles are shown in Table 1. It makes clear that value outperforms growth under this period. Another key result is that the median strategies perform better than the 30-70 strategies. The 'overall best' rows in Table 1 show how often value strategies outperform their competitors. Note that median value persistently outperforms other styles and the benchmark index. Table 1 also reports median P/BVs for 2001 and 05, note the expansion in value styles and contraction in growth styles. Also earnings yields are reported, and they decrease moving from value to growth.

We also looked at the performance of different styles when the index return is negative (22 of 60 months), but could not find any systematic patterns. Thus, we dismiss the claim that value stocks perform poorly in bad states of the economy, when the marginal utility of consumption is high. In fact, Figure 1 shows that the down-market performance of value styles is not unusual. Also, Chan and Lakonishok [4] survey value and growth performance during bull and

\footnotetext{
${ }^{3}$ The sample space includes five companies whose $\mathrm{P} / \mathrm{BV}$ is positive at the start (in 2001) but negative at the end (in 2005).
} 
bear markets without finding any material differences.

\begin{tabular}{|c|c|c|c|c|c|}
\hline Portfolio & $\begin{array}{l}30-70 \\
\text { value }\end{array}$ & $\begin{array}{c}\text { median } \\
\text { value }\end{array}$ & $\begin{array}{l}30-70 \\
\text { growth }\end{array}$ & $\begin{array}{l}\text { median } \\
\text { growth }\end{array}$ & $\begin{array}{l}\text { MSCI } \\
\text { Europe }\end{array}$ \\
\hline mean return $(\%)$ & 0.704 & 0.797 & 0.244 & 0.441 & 0.611 \\
\hline st.dev. (\%) & 5.33 & 5.14 & 3.89 & 4.16 & 4.51 \\
\hline bootstrap p-value & 0.264 & 0.070 & 0.025 & 0.005 & \\
\hline Sharpe ratio & 0.091 & 0.112 & 0.006 & 0.053 & 0.086 \\
\hline $\begin{array}{l}\text { Simulated Sharpe ratio } \\
\text { over index, ( } \% \text { of time) }\end{array}$ & 50.8 & 55.3 & 37.5 & 44.4 & \\
\hline overall best & & $36 / 60$ & & $18 / 60$ & $6 / 60$ \\
\hline overall best & $30 / 60$ & & $12 / 60$ & & $18 / 60$ \\
\hline median P/BV 01 & 1.20 & 1.42 & 5.25 & 3.76 & \\
\hline median P/BV 05 & 1.64 & 1.81 & 3.75 & 3.19 & \\
\hline median EY 01 (\%) & 6.14 & 5.79 & 2.91 & 3.66 & \\
\hline median EY 05 (\%) & 7.37 & 6.83 & 4.79 & 5.32 & \\
\hline number of stocks & 160 & 266 & 160 & 265 & 600 \\
\hline
\end{tabular}

Table 1: Descriptive statistics of value and growth styles. All returns are calculated on monthly basis over the period 1/2002-12/2006 (60 months). Mean risk-free rate is $0.222 \%$ per month. Bootstrap p-values are onesided, and they are based on the null that the style-index return spread is zero. 'Simulated Sharpe ratio over index' is calculated from 10,000 resampled values. The 'overall best' rows tell how often a given portfolio performs best during 60 months. 'MSCI Europe' is the total return index incl. dividends.

Figure 2 compares empirical Sharpe ratios. Value strategies offer better riskreward trade-off, although they are riskier. One-sided bootstrap p-values are calculated using the method of Wang [19]. The return distribution is resampled 10,000 times to produce t-statistics for the style-index return spread ${ }^{4}$. We can reject the null that median value-index return spread is zero with p-value of 0.07. We can also reject the null for both growth styles in favor of negative

\footnotetext{
${ }^{4}$ More formally, the $t$-statistic is $t=\left(r_{j}-r_{i}\right) / s d\left(r_{j}-r_{i}\right)$, where $r_{j}$ is return on style $j$ and $r_{i}$ is the index return, and $s d(\cdot)$ is standard deviation. P-values are calculated as $\operatorname{Pr}\left[\sqrt{N}\left(t_{b}-t_{0}\right)>\sqrt{N} \cdot t_{0}\right]$ when the spread is positive and $\operatorname{Pr}\left[\sqrt{N}\left(t_{b}-t_{0}\right)<\sqrt{N} \cdot t_{0}\right]$ when the spread is negative. $t_{b}$ is the bootstrap value, and $t_{0}$ is $t$-statistic under the null. We used a stationary bootstrap that requires stationarity of style returns. Stationarity was confirmed by Augmented Dickey-Fuller regressions. In practice we used the tseries package of $\mathrm{R}$ language.
} 
return spreads. All three rejections agree with the time-series of returns plotted in Figure 1. It also shows the case of 30-70 value against the index is undecided.

We prefer not to scale the Sharpe ratios for longer periods, because such extensions may result in very attractive figures that are unwarranted. Campbell and Viceira [3] point out that normally distributed returns imply the mean grows in proportion with time, but standard deviation grows with square root of time. Therefore extending the Sharpe ratios usually improves them. Also, we have no overlap in return series that would cause autocorrelation and downward bias in volatility.

Calculating the Sharpe ratios over a five-year period raises the question, whether the outperformance of value styles is due to random chance. Partial answer is found in Table 1. It reports how often the resampled style-level Sharpe ratios outperform the index, based on resampling the return distribution 10,000 times. We find that the odds for median value to outperform the index are $55: 45$. For $30-70$ value the odds are almost even at $51: 49$. In contrast, for growth strategies the odds are below $50: 50$, indicating their expected Sharpe ratios are below the index. In summary, these numbers agree with the actual Sharpe ratios that are fairly close (with the exception of 30-70 growth).

\begin{tabular}{|rccccc|}
\hline & $\begin{array}{c}30-70 \\
\text { value }\end{array}$ & $\begin{array}{c}\text { median } \\
\text { value }\end{array}$ & $\begin{array}{c}30-70 \\
\text { growth }\end{array}$ & $\begin{array}{r}\text { median } \\
\text { growth }\end{array}$ & $\begin{array}{c}\text { MSCI } \\
\text { Europe }\end{array}$ \\
\cline { 2 - 6 } 30-70 value & 1 & & & & \\
median value & 0.9913 & 1 & & & \\
$30-70$ growth & 0.8781 & 0.9045 & 1 & & \\
median growth & 0.9422 & 0.9645 & 0.9621 & 1 & \\
MSCI & 0.9679 & 0.9857 & 0.9492 & 0.9930 & 1 \\
\hline
\end{tabular}

Table 2: Correlations of $\log$ returns to value and growth style returns. All figures are calculated on monthly basis over the period 1/2002-12/2006 (60 months). The benchmark is MSCI Europe total return index.

Table 2 shows that returns to different styles are highly correlated, which indicates the styles usually move in tandem, although by different magnitudes. For practical managers these figures are good news to the extent that high correlations lead to small tracking error. On the other hand, it is difficult to reconcile the close alignment of value and growth returns with multifactor models. If there was a value factor in returns, it is unlikely that the 30-70 styles were closely aligned, as confirmed by correlation of 0.88 and Figure 1. 
It can be checked from Figure 1 that $30-70$ value is close to an index proxy, whereas 30-70 growth produces negative alphas. Also, as reported in Table 1, 30-70 value outperforms 30-70 growth and the index less frequently than median value outperforms median growth and the index. The evidence on returns and correlations provides some support for the nonrisk-based explanation, i.e. that investors irrationally avoid value stocks.

In particular, what properties of value stocks do investors dislike? Figure 5 shows that value firms are 'distressed' in the sense that their operating margins are low, and sometimes even negative at the start. Value firms are also more 'risky' in that their earnings exhibit higher variance than growth stocks, as shown by the earnings yield chart. This is in line with the higher betas of value stocks from Table 3. Further, value stocks show much lower returns on invested capital than growth stocks. Therefore value stocks may not seem 'prudent investments' at the start. But the point is that during the five-year period value stocks improve their profitability and return on invested capital materially, which leads to higher valuations as verified by Figure 4 .

Figure 5 also shows that growth stocks' operating margin and return on invested capital are almost flat. This may disappoint investors, if growth $\mathrm{P} / \mathrm{BV}$ multiples represent high expectations in those dimensions. Nevertheless, both growth styles beat their value counterparts when it comes to sales growth. The reader may decide, if the margin is too narrow to justify the name 'growth'. A similar result is reported by Jiang and Koller [10], who find that growth stocks have median sales growth of $10.1 \%$, whereas the median for value stocks is $8.7 \%$, and argue that growth stocks have 'no advantage in growth'.

\subsection{Excess returns to style portfolios and the maximum Sharpe ratio}

CAPM estimates for different styles are reported in Table 3. Panel A shows value stocks have higher betas than growth stocks, a finding that is at odds with some earlier evidence claiming there would be no difference in CAPM betas. The news from estimated alphas is mixed in the sense that only the median growth alpha is highly significant (and negative), but the alphas cannot be ignored when treated together. The null hypothesis of zero CAPM alphas can be rejected with $p$-value of 0.0804 , as reported in panel B of Table 3. This shows that even though the $t$-statistics of single alphas are modest. Under the alternative hypothesis $(\alpha \neq 0)$ distribution of the test statistic $\theta_{1}$ is $F_{4,55}(9.62)$. 
It is characteristic of the F-test that the null hypothesis holds when estimated alphas and the noncentrality parameter are close to zero. In contrast, under the alternative both the alphas and noncentrality parameter are large. Note that the noncentrality parameter (10) increases as the variance of alphas decreases, implying it is especially large when the excess returns are followed by a small increase in risk. Further, under the alternative hypothesis $s_{h}^{2}$ is large, suggesting that the benchmark index is far from efficient. Density functions for $\theta_{1}$ under the null and alternative hypotheses are plotted in Figure 3. It shows very clearly that if we reject the null, the range of $\theta_{1}$ and hence the range of possible Sharpe ratios, become wider.

\begin{tabular}{|c|c|c|c|c|c|}
\hline \multicolumn{2}{|l|}{ Portfolio } & $\begin{array}{l}30-70 \\
\text { value }\end{array}$ & $\begin{array}{c}\text { median } \\
\text { value }\end{array}$ & $\begin{array}{r}30-70 \\
\text { growth }\end{array}$ & $\begin{array}{l}\text { median } \\
\text { growth }\end{array}$ \\
\hline \multirow[t]{5}{*}{ A. CAPM } & alpha $\left(10^{-3}\right)$ & 0.365 & 1.372 & -2.972 & -1.385 \\
\hline & $\left(\right.$ s.e. $\left.\left(10^{-3}\right)\right)$ & $(1.748)$ & $(1.129)$ & $(1.600)$ & $(0.640)$ \\
\hline & beta & 1.144 & 1.124 & 0.820 & 0.918 \\
\hline & (s.e.) & $(0.0389)$ & $(0.0251)$ & $(0.356)$ & $(0.014)$ \\
\hline & $R^{2}$ & 0.936 & 0.971 & 0.900 & 0.986 \\
\hline \multirow[t]{2}{*}{ B. F-test } & $\theta_{1}$ & 2.204 & & $\lambda$ & 9.618 \\
\hline & $p$ & 0.0804 & & & \\
\hline \multirow[t]{5}{*}{ C. Efficiency } & ave $\psi_{p}$ & 0.85 & & $\mathrm{sd}\left(\psi_{p}\right)$ & 0.18 \\
\hline & $\min \psi_{p}$ & 0.34 & & $\max \psi_{p}$ & 0.99 \\
\hline & $\widehat{s}_{h}^{2}$ & 0.0755 & & $\operatorname{var}\left(\widehat{s}_{h}^{2}\right)$ & $8.411^{*} 10^{-3}$ \\
\hline & \multicolumn{3}{|c|}{$90 \%$ confidence bounds for $\widehat{s}_{h}^{2}$} & & {$[0,0.2268]$} \\
\hline & \multicolumn{3}{|c|}{ Max Sharpe ratio $\widehat{s}_{q}=\sqrt{\widehat{s}_{h}^{2}+\widehat{s}_{p}^{2}}$} & & 0.288 \\
\hline
\end{tabular}

Table 3: Panel A contains estimated CAPM parameters for the style portfolios. Panel B reports results of the MacKinlay [16] F-test. Panel C reports the Kandel and Stambaugh [12] relative efficiency measure $\psi_{p}$, as well as estimated parameters for the optimal orthogonal portfolio and the maximum Sharpe ratio. All calculations use monthly returns.

Panel C of Table 3 is about the efficiency of index portfolio. It reports first the relative efficiency measure of Kandel and Stambaugh [12], denoted $\psi_{p}$. The average $\psi_{p}$ in our data is 0.85 with standard deviation of 0.18 . Note that the maximum $\psi_{p}$ is 0.99 . Table $3 \mathrm{C}$ also gives the MacKinlay upper bound (11) of 0.1603 for $s_{h}^{2}$, based on the estimated noncentrality parameter of 9.62. Further, applying equation (12) gives an estimate of 0.0755 for $s_{h}^{2}$. Adding this to the 
squared Sharpe ratio of the benchmark index yields 0.288 for the Sharpe ratio of the efficient portfolio. This figure should be compared with the ex post ratios of 0.086 for the index and 0.112 for the median value. It is hardly surprising that simple ex ante strategies can capture only a small share of the benchmark inefficiency.

We cannot resist a little play with the numbers to show the implied market price of risk of the 'value risk factor', if there was one. Associate the difference of $0.288-0.086=0.202$ to a value risk factor orthogonal to the index. Assume that the expected return equals the mean excess return on index, which is $0.3897 \%$ per month. This implies a monthly standard deviation of appr. $1.93 \%$ for the risk factor, less than half of $4.52 \%$, the monthly standard deviation of excess returns on the index.

\subsection{Valuation dynamics and style migration}

Here we ask, how relative valuations change over time and what kind of firms improve their relative valuation. Previous research finds that valuation multiples have some predictive power, but autocorrelated errors and nonstationary regressors cause problems in inference (see Lewellen [14] and references therein). Cohen, Polk and Vuolteenaho [5] survey a panel data of BE/ME ratios of US equities using $40 \mathrm{BE} / \mathrm{ME}$-sorted portfolios. They decompose the variance of demeaned log BE/ME (the inverse of $\mathrm{P} / \mathrm{BV}$ ) in a 15-year panel to three components and find that about $20 \%$ is associated with expected stock returns and $55 \%$ is associated with expected profitability (ROE). This leaves $25 \%$ to residual variance, or the persistent component of book-to-market ratio.

Figure 4 shows the $\mathrm{P} / \mathrm{BV}$ distributions for different styles, estimated at the start $(12 / 2001)$ and after four years $(12 / 2005)$. At the start the estimated densities (thick lines) are cut at the style breakpoints. Looking at the first panel, the highest $\mathrm{P} / \mathrm{BV}$ (at the start) for 30-70 value, equal to the breakpoint, is 1.55. Vertical lines are drawn at within-style medians. Comparing them shows that the median $\mathrm{P} / \mathrm{BV}$ of value stocks increases for both pairs, whereas the multiple on growth stocks decreases. Another point from Fig. 4 is that the $\mathrm{P} / \mathrm{BV}$ distributions of value stocks became less concentrated around their means over time. The changing shapes imply that some value stocks become growth stocks, and the reverse is also possible. Nevertheless, the valuation gap between value and growth stocks but it does not disappear. Median P/BV levels are reported in Table 1. 
Table 4 looks at style migration, that is the movement from value to growth and the other way round. When a value stock migrates to growth, its valuation increases relative to the market, and therefore style migration is different from multiple expansion. The odds for a typical median value stock to stay in median value are 7.2 times the odds for a median growth stock to move to median value. Despite the fact that most value stocks stay in their initial style, some of them (73 of 257) improve their relative valuation enough and move to the median growth style. Panels B and C of Table 4 feature average monthly returns and Sharpe ratios of the movers and stayers across styles. Clearly, the winners from style migration are the value stocks that become growth stocks. Their monthly return is $1.13 \%$ and Sharpe ratio is 0.221 , an outstanding number when compared with median value and benchmark index figures of 0.112 and 0.086 .

\begin{tabular}{|rccc|}
\hline A. Counts of movers and stayers & & \\
median value 01 & median value 05 & median growth 05 & style total \\
\cline { 2 - 3 } median growth 01 & 184 & 73 & 257 \\
style total & 252 & 194 & 262 \\
B. Monthly returns $(\%)$ & & 267 & 519 \\
& median value 05 & median growth 05 & style total \\
\cline { 2 - 3 } median value 01 & 0.742 & 1.129 & 0.797 \\
median growth 01 & 0.262 & 0.530 & 0.441 \\
C. Monthly Sharpe ratios & & \\
\cline { 2 - 3 } & median value 05 & median growth 05 & style total \\
median value 01 & 0.096 & 0.221 & 0.112 \\
median growth 01 & 0.007 & 0.083 & 0.053 \\
\hline
\end{tabular}

Table 4: Style migration. Panel A reports the counts of movers and stayers. The odds for 'value stock stays in value' are $184 / 73=2.52$. Similarly, the odds for 'growth stock moves to value' are 68/194 $=0.35$. The odds ratio is appr. 7.2:1 and using Fisher's exact test we can reject the null that odds ratio equals $1: 1$ with a p-value of $2.2^{*} 10^{-16}$. Panel B prints average monthly returns, and Panel $\mathrm{C}$ gives monthly Sharpe ratios. Average risk-free return is $0.222 \%$ per month.

In order to find what causes style migration, we estimated a logit model for the probability that a given stock ends up in the median growth style. Because 
the response variable is not return, this model avoids problems with inference common in predictive regressions. Predicting the actual level of $\mathrm{P} / \mathrm{BV}$ would be unwise, since it cannot be ruled out that the scaled stock price follows random walk. In theory, this must be the case if investors have rational expectations, as shown by Roll [18]. Our model does not require P/BV to be stationary, because the cutoff point varies from year to year. This way the model adjusts for market-wide multiple expansion.

Equation (15) defines the style migration model, where the response variable is the logit of $p=\operatorname{Pr}\left(P / B V_{\text {final }}\right.$ is over the median). There are three covariates; Value $_{01}$ is an indicator that takes value 1 for median value stocks (in 2001) and 0 for median growth stocks (in 2001). ROIC is the average return on invested capital for the applicable period, and $E Y$ is the average earnings yield. $R O I C$ and $E Y$ are measured in percentage points, that is $10 \%$ return on invested capital corresponds to $R O I C$ value of 10 . We also tried to include average operating margin as covariate in the style migration model, but it didn't add any explanatory power.

$$
\log \left(\frac{p}{1-p}\right)=\beta_{0}+\beta_{1} \text { Value }_{01}+\beta_{2} \text { ROIC }+\beta_{3} E Y
$$

Maximum likelihood estimates for style migration model are given in Table 5. The likelihood ratio (LR) statistics imply that the covariates have explanatory power as a group ${ }^{5}$. If we look at the period 2001-05, the coefficient of Value 01 suggests that the odds for a value stock moving to growth are $e^{-1.7947}=0.1662$, if everything else is held constant. Note that the estimated $\beta_{1}$ values increase from -3.1 to -1.8 as the period becomes longer, implying that the likelihood of large changes in relative valuation grows with time. All the $\beta_{1}$ values are significant at $0.1 \%$ level.

Another key finding from Table 5 is that end-of-period growth stocks tend to have high ROIC, and the effect remains significant after controlling for initial style orientation and earnings yield. All estimated ROIC coefficients reported in the $\beta_{2}$ column are highly significant and positive. The finding that high ROIC predicts high end-of-period P/BV is in line with Cohen, Polk and Vuolteenaho [5], who report that some $40 \%$ of the cross-sectional variation in demeaned $\mathrm{BE} / \mathrm{ME}$ is related to expected profitability (measured by ROE). Also, Jiang and Koller [10] report that growth stocks have higher average ROIC than value

\footnotetext{
${ }^{5}$ An analysis of deviance table (not reported here) shows that each covariate adds explanatory power.
} 
stocks, based on studying the S\&P 500/ Barra Growth and Value indices.

The style migration model also features earnings yield, and Table 5 shows it has some predictive power over longer horizons. Negative coefficients on EY are explained by the fact that $\mathrm{P} / \mathrm{BV}$ is proportional to stock price, whereas earnings yield is inversely proportional to it. It is intuitive that stock with low average $\mathrm{E} / \mathrm{P}$ (high average $\mathrm{P} / \mathrm{E}$ ) tend to have high end-of-period $\mathrm{P} / \mathrm{BV}$. Indeed, the combination of significantly positive $\beta_{2}$ and negative $\beta_{3}$ indicates that the ROIC effect is not fully priced by the market by setting higher $\mathrm{P} / \mathrm{E}$ (lower earnings yield) on high-ROIC stocks.

\begin{tabular}{|l|llll|l|}
\hline period & \multicolumn{1}{l}{$\beta_{0}$} & $\beta_{1}$ & $\beta_{2}$ & $\beta_{3}$ & \multicolumn{1}{l|}{ med. final P/BV } \\
\hline \multirow{2}{*}{$2001-02$} & $1.3541^{* * *}$ & $-3.1024^{* * *}$ & $0.0383^{* *}$ & 0.0022 & 1.68 \\
& $(0.1837)$ & $(0.2388)$ & $(0.0127)$ & $(0.0063)$ & $\mathrm{LR}=269.73$ \\
& $1.1382^{* * *}$ & $-2.6809^{* * *}$ & $0.0336^{*}$ & $-0.0136^{*}$ & 2.00 \\
& $(0.1802)$ & $(0.2239)$ & $(0.01385)$ & $(0.0066)$ & $\mathrm{LR}=215.70$ \\
$2001-04$ & $0.9668^{* * *}$ & $-2.4671^{* * *}$ & $0.0417^{* *}$ & -0.0120 & 2.14 \\
& $(0.1846)$ & $(0.2195)$ & $(0.0152)$ & $(0.0071)$ & $\mathrm{LR}=195.02$ \\
$2001-05$ & $0.5395^{* *}$ & $-1.7947^{* * *}$ & $0.0652^{* * *}$ & $-0.0172^{*}$ & 2.33 \\
& $(0.1974)$ & $(0.2095)$ & $(0.0180)$ & $(0.0070)$ & $\mathrm{LR}=136.48$ \\
\hline
\end{tabular}

Table 5: Estimated coefficients for the style migration model (15). Standard errors are reported in parentheses below the coefficients. The med. final $\mathrm{P} / \mathrm{BV}$ column reports median $\mathrm{P} / \mathrm{BV}$ at the end of period and likelihood ratio (LR) test statistics that are $\chi^{2}(3)$ distributed. *, ** and *** indicate significance levels of $5 \%, 1 \%$ and $0.1 \%$, respectively.

Figure 6 presents the model fit for 2001-2005 by comparing estimated probabilities of being in median growth style (in 2005) to actual probabilities using ROIC as grouping variable. The fitted curves look different, because Value $_{01}=$ 1 on the left, whereas Value $_{01}=0$ on the right. The actual probabilities (dots) are calculated as proportions of end-of-period growth stocks within ROIC groups. The curves are plotted using medians of EY within the median value and growth styles (the values are $5.74 \%$ and $4.51 \%$, respectively). In general the actual and estimated probabilities agree. In the left panel the is a single outlier, resulting from the fact that all stocks in the highest ROIC-value group stay in their initial style (however, there are only 2 stocks in this group). 


\section{Conclusions}

Based on returns and accounting data on 531 largest European stocks, we find that the benchmark index is inefficient, and a simple buy-and-hold value strategy outperforms the index in terms of returns and Sharpe ratio. However, such ex ante strategy is able to capture only a minor share of the benchmark index inefficiency. Strong performance of value is consistent with the claim of Fama and French [7] that value returns result from market overreaction to the relative prospects of firms. If overreaction tends to be corrected, price-to-book value associates with the cross section of stock returns.

Investors may avoid value stocks because their initial profitability, measured by operating margin, is low but improves significantly over the research period. Another reason for avoiding value stocks and preferring growth stocks is that growth stocks report consistently higher return on invested capital. Moreover, the earnings of value stocks appear riskier when measured by operating margin or earnings yield.

Also, we report style migration among stocks. Value firms with high return on the book value of equity and debt are likely to improve their relative valuation and some of them become growth stocks. However, the odds for a growth stock to stay in the growth category are about seven times the odds for a value stock to enter the growth category. The stocks that migrate from median value to median growth provide higher returns and Sharpe ratios than the index and other value stocks.

The style migration model is consistent with two empirical stylized facts. First, the positive coefficient on ROIC highlights that growth stocks do very well in ROIC rankings, because ROIC compares net income and interest payments against the book value of equity and debt. Second, the negative slope on EY testifies that in earnings yield rankings, where earnings are compared against the market value of equity, the likely winners are value stocks.

\section{A Appendix: Squared Sharpe ratio of the opti- mal orthogonal portfolio}

We know that $\theta_{1}$, defined by eq. (8), is a random variable following noncentral $F$ distribution with $N$ and $T-N-1$ degrees of freedom and noncentrality parameter $\lambda$. We use formulas 3.1 and 3.2 given in chapter 30 of Johnson 
and Kotz [11] for the mean and variance of a noncentral $F$ variate to get the expressions for $\theta_{1}$.

$$
\begin{aligned}
E\left(\theta_{1}\right) & =\frac{(\lambda+N)(T-N-1)}{N(T-N-3)} \\
\operatorname{var}\left(\theta_{1}\right) & =2\left(\frac{T-N-1}{N}\right)^{2}\left[\frac{(\lambda+N)^{2}+(N+2 \lambda)(T-N-3)}{(T-N-3)^{2}(T-N-5)}\right]
\end{aligned}
$$

These formulas require that the number of time periods is somewhat larger than the number of portfolios, i.e. that $T-N>5$. We start by calculating an estimator for the squared Sharpe ratio of the optimal orthogonal portfolio, denoted $\widehat{s_{h}^{2}}$. Recall that the estimated value of the noncentrality parameter is

$$
\lambda=T \widehat{s_{h}^{2}} /\left(1+\mu_{p}^{2} / \sigma_{p}^{2}\right)=T \widehat{s_{h}^{2}} / \kappa,
$$

using the acronym $\kappa=1+\mu_{p}^{2} / \sigma_{p}^{2}$. Combining equations (A1) and (A3) gives

$$
\left[\frac{N(T-N-3)}{T-N-1}\right] \widehat{\theta}_{1}=\frac{T \widehat{s_{h}^{2}}}{\kappa}+N
$$

Note that we need the property $E\left(\widehat{\theta}_{1}\right)=\theta_{1}$, i.e. $\widehat{\theta}_{1}$ is an unbiased estimator. Rearranging terms produces the desired formula for expected value of the squared Sharpe ratio.

$$
\widehat{s_{h}^{2}}=\left[\widehat{\theta}_{1}-\frac{(T-N-1)}{(T-N-3)}\right]\left[\frac{N(T-N-3)}{T(T-N-1)}\right] \widehat{\kappa}
$$

The variance of $\widehat{s_{h}^{2}}$ is calculated by combining the noncentrality parameter (A3) with the formula for variance (A2). First we rewrite the previous formula (A4) for Sharpe ratio yielding (A5).

$$
\widehat{s_{h}^{2}}=a\left[\widehat{\theta}_{1}-\frac{(T-N-1)}{(T-N-3)}\right]
$$

In eq. (A5) $a$ is positive constant that equals the product of two last terms in (A4). Then we simply use the rule $\operatorname{var}(a x)=a^{2} \operatorname{var}(x)$, which gives after some 
calculations the formula for variance of $\widehat{s_{h}^{2}}$.

$$
\operatorname{var}\left(\widehat{s_{h}^{2}} \mid \widehat{\kappa}\right)=\frac{2 \widehat{\kappa}^{2}}{T^{2}}\left[\frac{\left(T \widehat{\kappa}^{-1} \widehat{s_{h}^{2}}+N\right)^{2}+\left(2 T \widehat{\kappa}^{-1} \widehat{s_{h}^{2}}+N\right)(T-N-3)}{T-N-5}\right]
$$

\section{References}

[1] Barberis, N. and Thaler, R.H. Survey of behavioral finance. In Thaler, R.H. (ed.) Advances in behavioral finance Vol. II. Princeton University Press 2005.

[2] Breeden, D.T. (1979) An intertemporal asset pricing model with stochastic consumption and investment opportunities. Journal of Financial Economics 7: $265-296$.

[3] Campbell, J.Y. and Viceira, L.M. (2002) Strategic asset allocation. Portfolio choice for long-term investors. Oxford University Press.

[4] Chan, L.K.C. and Lakonishok, J. (2004) Value and growth investing: review and update. Financial Analysts Journal Jan/Feb 2004: 71-86.

[5] Cohen, R., Polk, C. and T. Vuolteenaho (2003) The value spread. Journal of Finance 58: 609-641.

[6] Fama, E.F. and French, K.R. (1995) Size and book-to-market factors in earnings and returns. Journal of Finance 50: 131-155.

[7] Fama, E.F. and French, K.R. (1996) Multifactor asset pricing anomalies. Journal of Finance 51: 55-84.

[8] Ferson, W.E. (2003) Tests of multifactor pricing models, volatility bounds and portfolio performance. Chapter 12 in Constantinides et al. (eds.) Handbook of the Economics of Finance. Elsevier 2003.

[9] Gibbons, M.R., Ross, S.R. and Shanken, J. (1989) A test of the efficiency of a given portfolio. Econometrica 57: 1121-1152.

[10] Jiang, B. and Koller, T. (2007) The truth about growth and value stocks. McKinsey on Finance Winter 2007. 
[11] Johnson, N.L. and Kotz, S. (1970) Continuous univariate distributions vol. 2. John Wiley and Sons.

[12] Kandel, S. and Stambaugh, R. (1995) Portfolio inefficiency and the crosssection of expected returns. Journal of Finance 50: 157-184.

[13] Lakonishok, J., Shleifer, A. and Vishny, R. (1994) Contrarian investment, extrapolation and risk. Journal of Finance 49: 1541-1578.

[14] Lewellen, J. (2004) Predicting returns with financial ratios. Journal of Financial Economics 74: 209-235.

[15] Lo, A.W. and MacKinlay, C.G. (1999) A Non-random walk down Wall Street. Princeton University Press.

[16] MacKinlay, C.G. (1995) Multifactor models do not explain deviations from the CAPM. Journal of Financial Economics 38: 3-28.

[17] Roll, R. (1980) Orthogonal portfolios. Journal of Financial and Quantitative Analysis 15: 1005-1023.

[18] Roll, R. (2002) Rational infinitely lived asset prices must be non-stationary. Journal of Banking and Finance 26: 1093-1097.

[19] Wang, K.Q. (2005) Multifactor evaluation of style rotation. Journal of Financial and Quantitative Analysis 40: 349-372. 

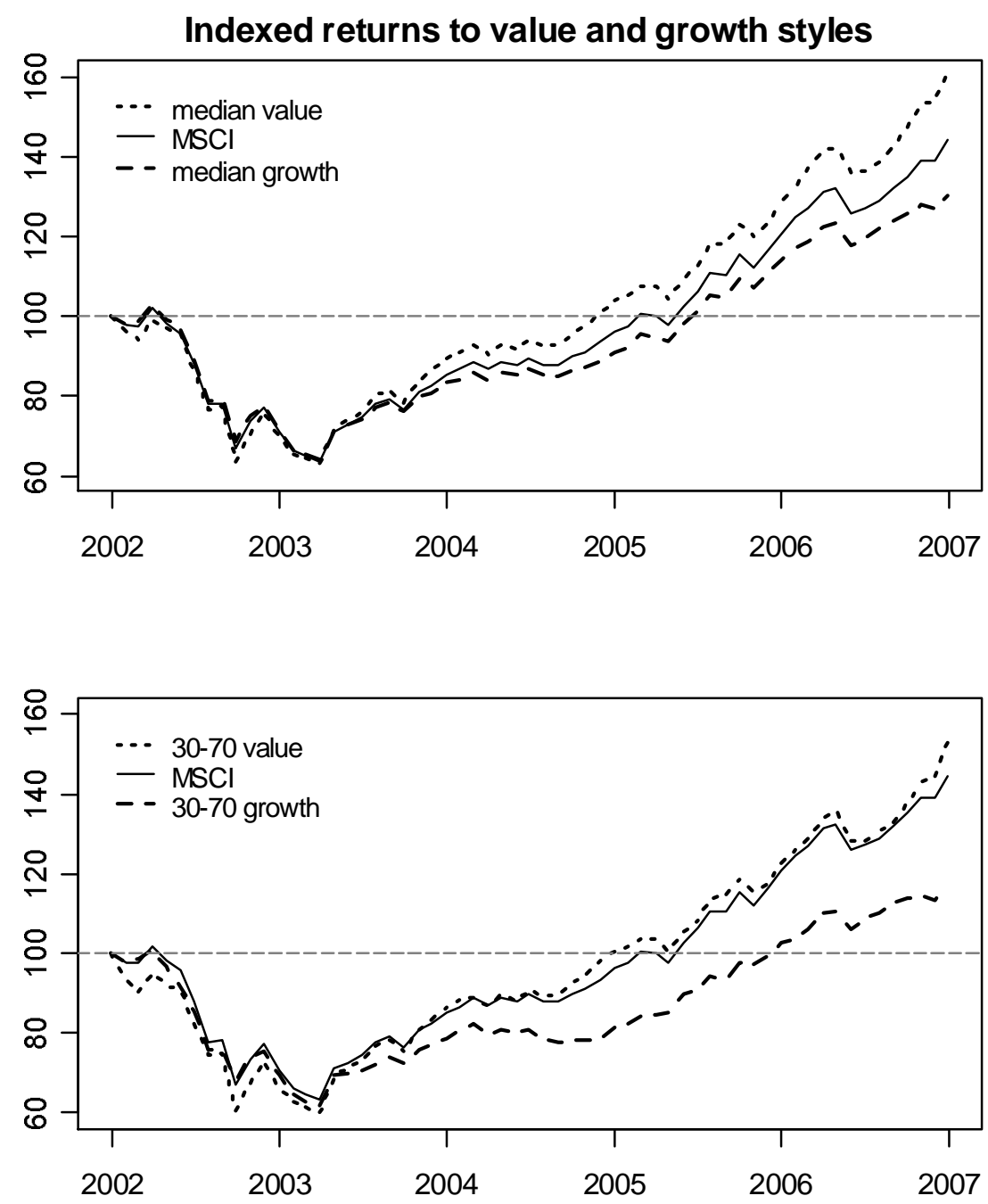

Figure 1: Indexed returns (total return indices from Datastream) for different styles. All returns are value-weighted, and there is no rebalancing. The benchmark is MSCI Europe total return index. 


\section{Monthly Sharpe ratios}
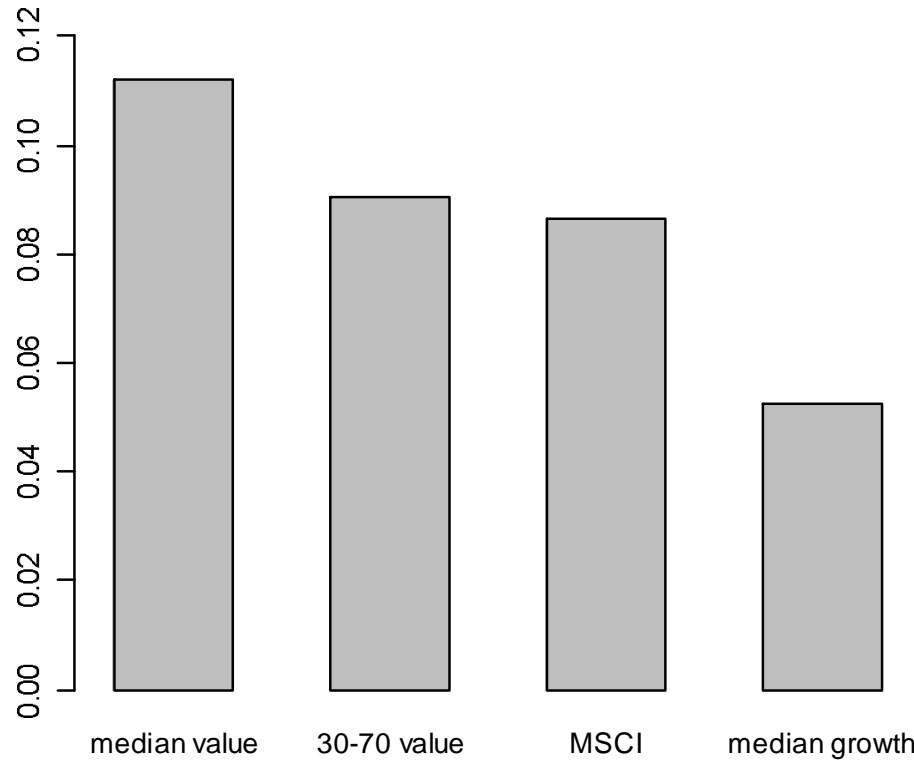

30-70 growth

Figure 2: Monthly Sharpe ratios, calculated over the period 1/2002-12/2006 (60 months) for our four styles and the benchmark (MSCI Europe total return index). 


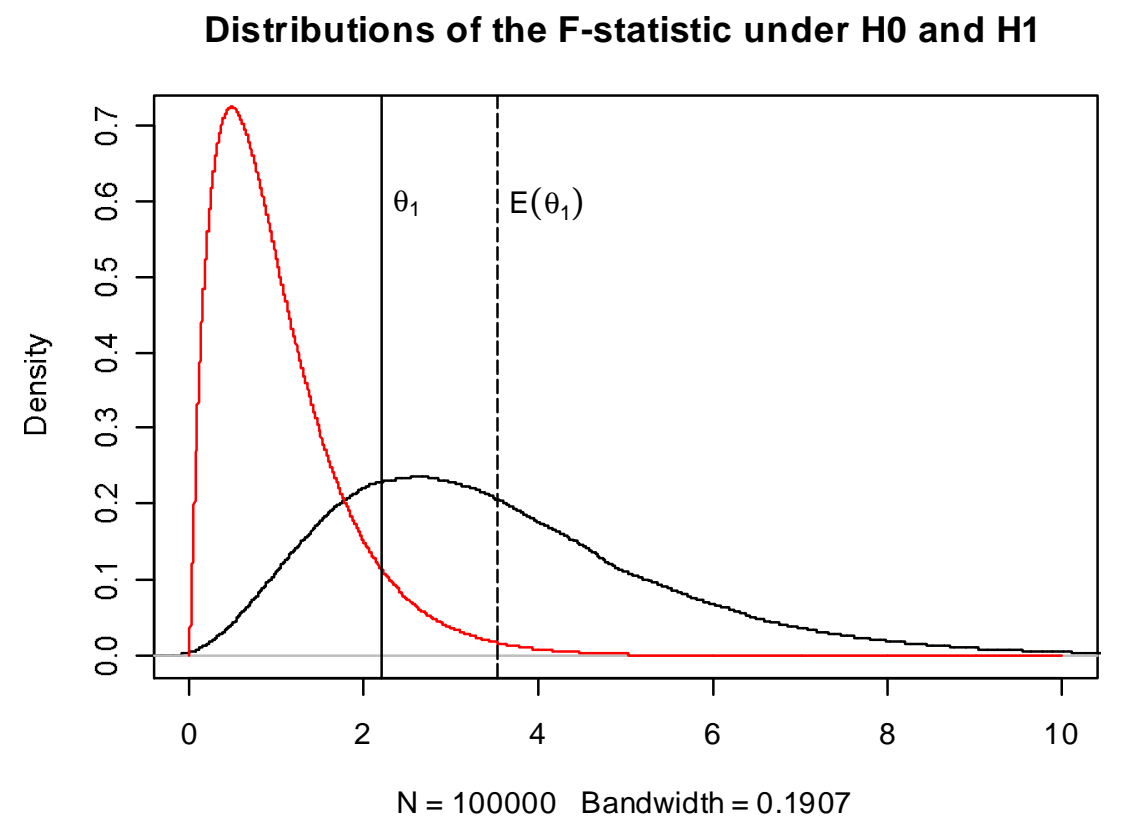

Figure 3: Probability density functions of the test statistic $\theta_{1}$ under the null and alternative hypotheses. The solid line plots estimated value of $\theta_{1}$, and the dashed line plots expected value of $\theta_{1}$ under the alternative. (Noncentral Fdistribution is simulated using the ratio of two chi-squared random variables, see Johnson and Kotz [11, Chapter 30.]) 

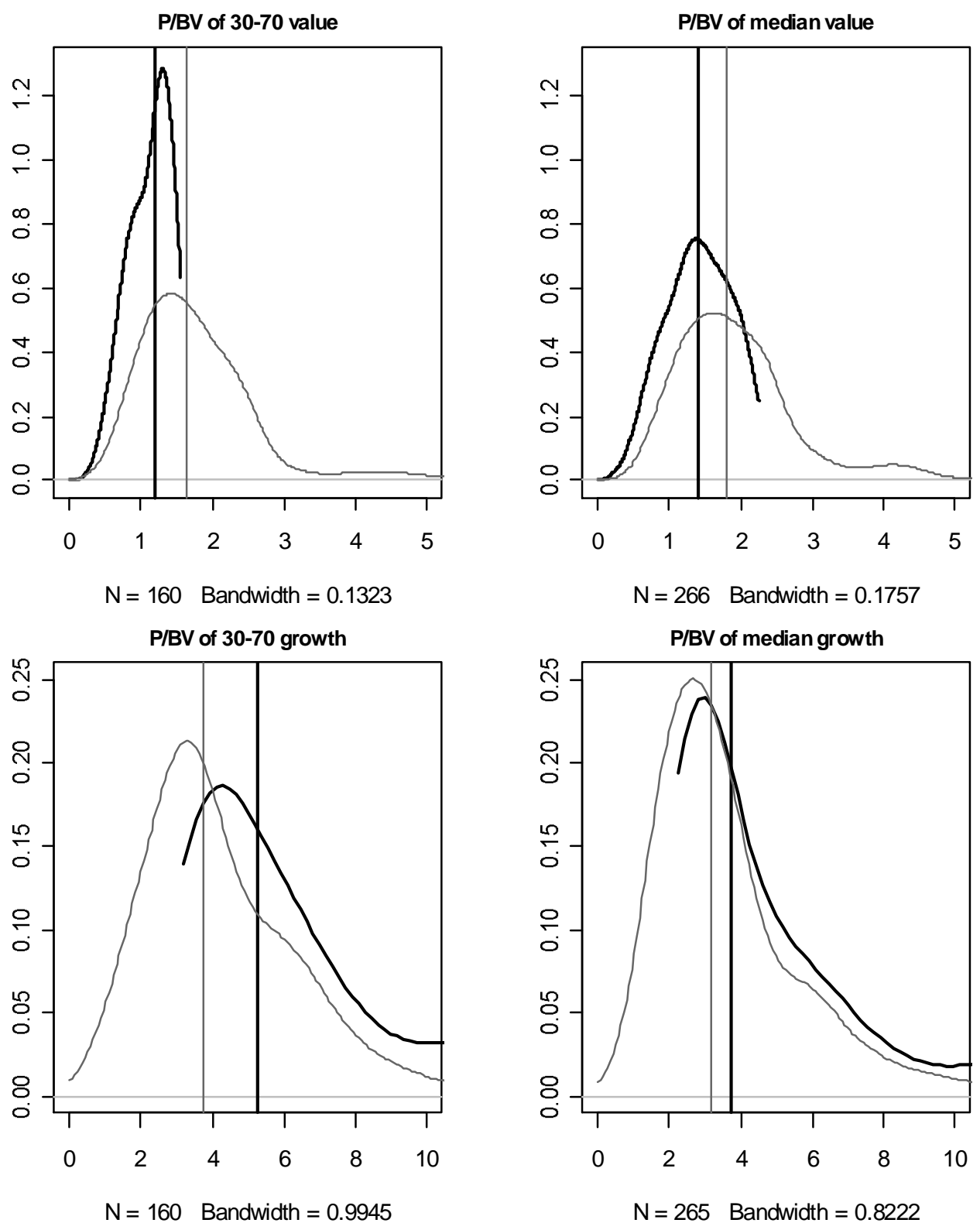

Figure 4: Distributions of $\mathrm{P} / \mathrm{BV}$ in different styles. Thick lines point estimated densities and within-sample medians at the start (12/2001), and thin lines point the same figures after four years $(12 / 2005)$. Actual values are reported in Table 1. Note that both $\mathrm{x}$ and $\mathrm{y}$-axis scales are different in upper and lower panels. 

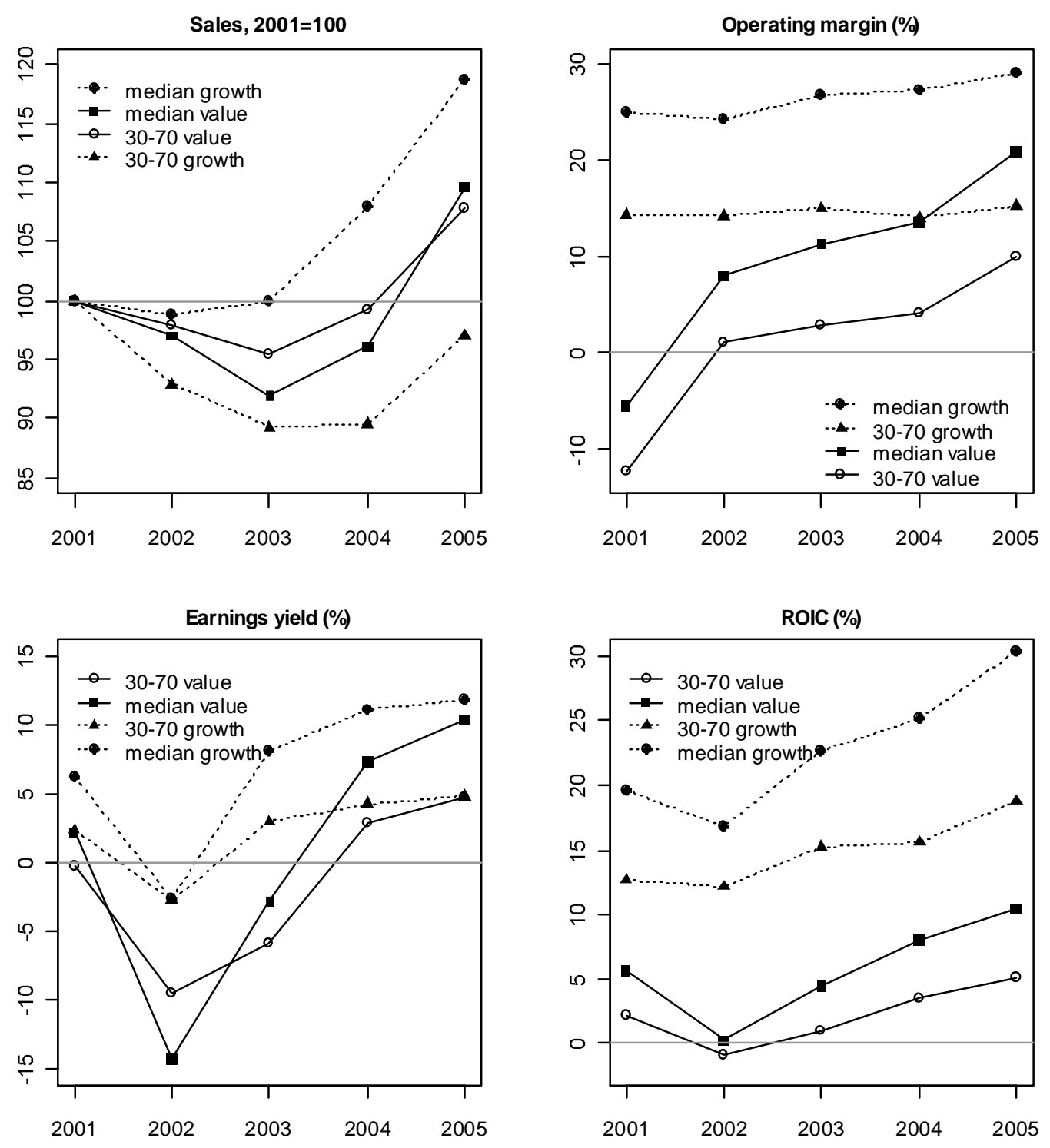

Figure 5: Development of sales, profitability, earnings yield and ROIC of value and growth styles. All figures are value-weighted, and they are based on annual firm-level data from Thomson Datastream and Worldscope. 

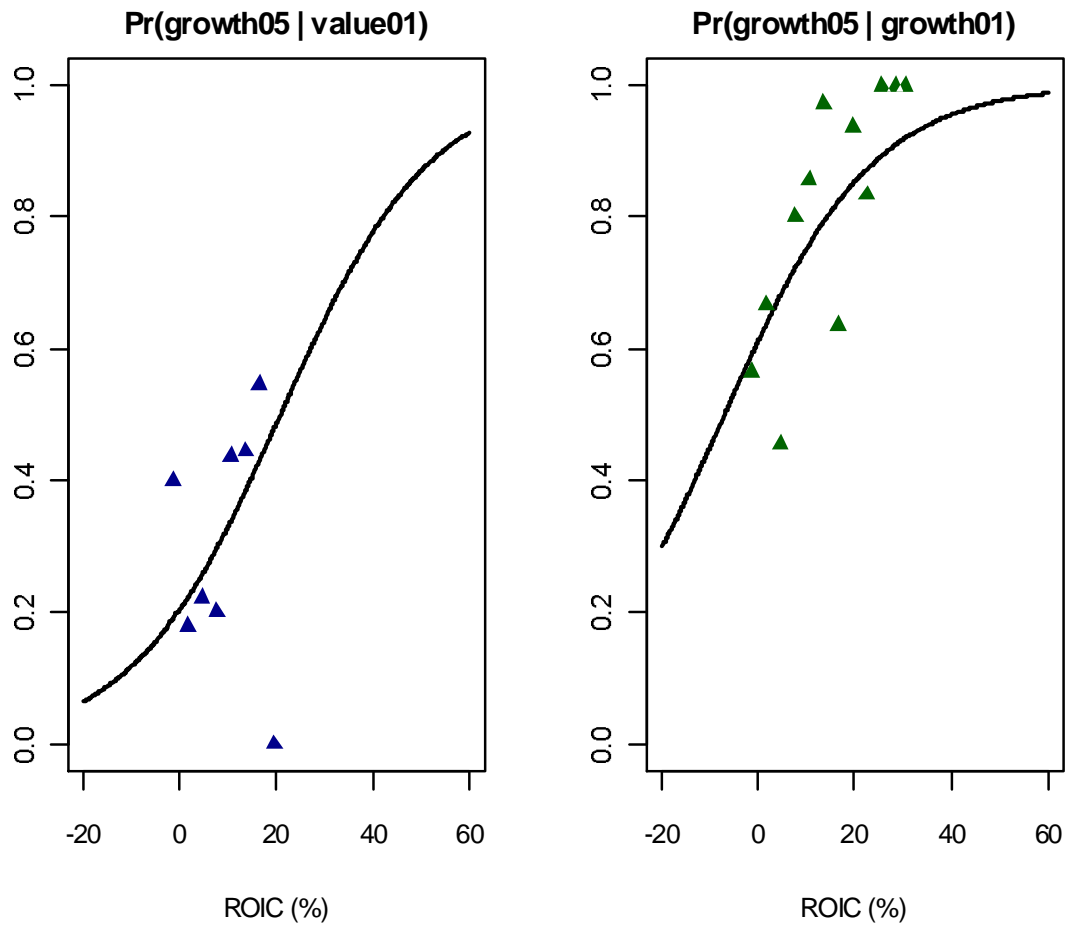

Figure 6: Style migration. The left panel shows the logit model fit for median value 2001 stocks. The right panel shows how well the model fits for median growth 2001 stocks. The curves are drawn using eq. (15) and they are different, because Value $_{01}=1$ on the left, but Value $01=0$ on the right. Solid lines plot estimated probabilities of being in the median growth style as function of ROIC, and the dots represent actual proportions based on ROIC groupings. 